\title{
Coronavirus Disease 2019: A threat to global health
}

\author{
Lisa Saa BS, Kenneth Iwuji MD
}

\begin{abstract}
Due to its rapid spread, the World Health Organization characterized coronavirus disease 2019 (COVID-19) as a pandemic on March 11, 2020. Coronaviruses cause a variety of respiratory diseases, ranging from the mild common cold to the lethal Middle East Respiratory Syndrome. At the end of 2019, COVID-19 made its way onto the global stage due to its rapid human-to-human transmission and its ability to cause death secondary to respiratory failure. Symptoms of lower respiratory illness, including cough and shortness of breath, along with fever, should raise suspicion of COVID-19 infection in those who have recently traveled to high-risk areas or have had close contact with a confirmed or suspected case of COVID-19. Other symptoms include gastrointestinal distress and cardiac involvement. Polymerase chain reaction testing of respiratory specimens and computed tomographic scans of the chest can be used to confirm the disease. Preventing exposure to the disease through handwashing, surface disinfection, and avoiding contact with those who are sick is the best way to prevent transmission of the disease. Many countries and local governments have implemented stayat-home orders to decrease the rapid spread of COVID-19. Management of the disease involves symptom control, as there is currently no available treatment, but many clinical trials are underway. Global health efforts have concentrated on quick and aggressive actions to slow the transmission of the disease and identify cases as quickly as possible but with varying degrees of success.
\end{abstract}

Keywords: coronavirus disease 2019, global health, respiratory illness, COVID-19

\section{INTRODUCTION}

The Coronaviridae family, a virus with zoonotic and human-to-human transmission, has an enveloped, positive-sense single-stranded ribonucleic acid genome. It received its name from its crown-like appearance in electron micrographs. The Coronaviridae family has been known to cause a variety of respiratory diseases, including the common cold, bronchitis, pneumonia, the Severe Acute Respiratory Syndrome (SARS), the Middle East Respiratory Syndrome (MERS), and most recently, the Severe Acute Respiratory Syndrome

Corresponding author: Lisa Saa

Contact Information: Lisa.saa@ttuhsc.edu

DOI: 10.12746/swrccc.v8i34.673 coronavirus 2 (SARS-CoV-2). SARS-CoV-2 is the virus responsible for coronavirus disease 2019 (COVID-19).

Although human coronaviruses have been traditionally known to cause mild upper respiratory tract infections, two deadly strains caused worldwide epidemics. In 2002-2003, SARS-associated coronavirus (SARS-CoV) affected a total of 8,098 people with 774 deaths across 29 countries and five continents, resulting in an overall case-fatality ratio (CFR) of $9.7 \%{ }^{1}$ SARS was first reported in China, and symptoms included fever, headache, body aches, mild respiratory symptoms, diarrhea, dry cough, and atypical pneumonia, with respiratory failure being the most common cause of death. Advanced age was the most predictive factor of an adverse event. ${ }^{2}$

Middle East Respiratory Syndrome (MERS)-associated coronavirus was first reported in Saudi Arabia 
in 2012. Although less contagious than SARS-CoV, it had higher mortality rates. The symptoms of MERSCoV are similar to SARS-CoV and include fever, cough, shortness of breath, pneumonia, and diarrhea. There were 1,841 confirmed cases with 652 deaths across 27 countries, resulting in an estimated CFR of $35 \% .^{3}$

In December of 2019, SARS-CoV-2 (previously known as 2019 novel coronavirus or 2019-nCoV) was first reported in China. The disease is characterized by fever, cough, and shortness of breath, with symptoms appearing 2-14 days after exposure. Asymptomatic carriers of COVID-19 are believed to be most infectious just prior to symptom onset. ${ }^{4}$ COVID-19 is transmitted primarily by close contact via respiratory droplets as well as contact with infected surfaces. ${ }^{5}$ In mid-January, there were about 300 confirmed cases, but as of March 31, 2020, there have been over 750,000 confirmed cases and 36,405 deaths across over 200 countries and territories. ${ }^{6}$

The CFR varies by region; in China, the estimated overall CFR is $2.3 \%$, whereas it is $7.2 \%$ in Italy, where the second outbreak occurred. When stratified by age, there is no difference in the CFR between the two countries for ages 0-69. However, for individuals older than 69 (37.6\% of the overall cases in Italy and $11.9 \%$ of the cases in China), the CFR is higher in Italy. Thus, the older aged population of Italy may explain the higher CFR. Furthermore, Italy chose to implement testing of COVID-19 in only those individuals with severe clinical symptoms on February 25th, potentially leaving those with mild cases undetected and causing an artificial inflation of the CFR. ${ }^{7}$ Because of multiple conflicting factors in an ongoing pandemic, the true CFR is impossible to approximate, with best estimates claiming it is lower than both MERS and SARS but higher than influenza $(0.1 \%){ }^{8}$

Furthermore, COVID-19 does not discriminate; it infects younger individuals and older individuals. Although the data are preliminary at this point, the U.S. has seen 6.5 cases per 1 million U.S. residents aged 20 to 44, compared to 22.0 in the $85+$ age group. However, $20 \%$ of people in the $20-44$ age group are hospitalized, with $12 \%$ requiring intensive care unit (ICU) admission. ${ }^{9}$ Younger individuals may have increased susceptibility in the U.S. due to higher rates of obesity and comorbidities, including diabetes mellitus and ischemic heart disease, which have been associated with increased mortality. ${ }^{7}$ Additionally, in China, smokers were more likely to have a severe course of COVID-19 and require ICU care, including mechanical ventilation. ${ }^{10}$ Considering that $27 \%$ of individuals in the U.S. in the 18-49 age group regularly use e-cigarettes and that smoking causes an increased risk, e-cigarettes may be contributing to high hospitalization rates in the younger population. ${ }^{11}$ This will be an important metric to follow in the upcoming months.

All three of these strains (SARS-CoV, MERS-CoV, and SARS-CoV-2) are believed to have originated in bats, with transmission to humans from civets, camels, and possibly seafood or an animal market, respectively. ${ }^{5}$ It is believed that SARS-CoV-2 underwent at least two viral mutations in November 2019, explaining the increased infectivity in humans. ${ }^{12}$ Human coronaviruses have also been shown to have significant environmental resistance and can survive in respiratory secretions, feces, and serum. The cross-species transmission of human coronaviruses, along with their environmental resistance, explains their dynamic nature and their ability to cause epidemics. ${ }^{13}$

\section{Diagnosis}

COVID-19 is primarily a respiratory illness, with the primary symptoms being fever, cough, and shortness of breath. The respiratory symptoms may be preceded by loss of smell or taste and by gastrointestinal upset, including diarrhea and nausea. Serious complications include bilateral pneumonia, respiratory failure, cardiac injury, multiple organ dysfunction, septic shock, cytokine storm, and death, with $5 \%$ of cases falling in the critical illness severity range and $81 \%$ experiencing mild to moderate symptoms. ${ }^{5,14}$

Because human-to-human transmission occurs, a high level of suspicion is needed for patients who have recently traveled to high-risk areas or have had contact with a confirmed case of COVID-19 and have a fever or lower respiratory illness symptoms. However, considering the worldwide spread and ability of asymptomatic individuals to shed the virus, most individuals 
have been exposed to an undetected case, such as in passing, and clinical symptoms alone should raise suspicion. ${ }^{5}$

Patients with COVID-19 may present with laboratory abnormalities, including lymphopenia, neutrophilia, and elevated liver enzymes, lactate dehydrogenase, ferritin and C-reactive protein. More severe cases are associated with elevated D-dimer levels and lymphopenia. Chest radiographs will often show bilateral air-space consolidation. ${ }^{5}$ Typical CT findings include bilateral ground glass opacities in the lower lobes with atypical findings, including central ground glass opacities and peripheral linear opacities. . $^{5,15,16}$

The Centers for Disease Control and Prevention (CDC) has developed a laboratory test utilizing polymerase chain reaction (PCR) of upper and lower respiratory specimens in patients with suspected COVID-19. The test was distributed to international laboratories with the intent of hastening the time to receive results. However, because of performance issues, the test's accuracy could not be verified, and respiratory samples could be sent only to a few public health labs and the CDC. ${ }^{5}$ Since then, the CDC has improved the test and 94 public health labs in the U.S. can participate in testing. Private companies and universities have developed their own testing kits, enabling more individuals to be tested with quicker turnaround times as they can be processed in hospital labs or large commercial labs. ${ }^{17}$

A study has shown, however, that chest computed tomographic (CT) scans with abnormal findings are more sensitive at detecting COVID-19 in highrisk individuals compared to real-time PCR at $98 \%$ and $71 \%$, respectively, in a sample of 51 patients. ${ }^{15}$ Furthermore, CT scans had higher sensitivity than real-time reverse-transcriptase PCR at initial presentation. ${ }^{16}$ Overall, considering the rapid spread, most physicians are able to diagnose patients based on history and physical examination alone, as most cases present comparably.

\section{Prevention and treatment}

To prevent exposure to COVID-19, the CDC recommends everyday preventative actions similar to those of other respiratory illnesses. These include avoiding contact with people who are sick, disinfecting frequently touched objects, and washing hands often. ${ }^{5}$ Because the number of cases are exponentially rising, many countries have called for isolation within their communities, including stay-at-home orders with exceptions for essential travel and emergencies. Currently, no vaccine is available.

In the hospital setting for suspected or confirmed infections, the World Health Organization (WHO) recommends standard, contact, and droplet precautions with eye or face protection. Airborne precautions should be utilized during aerosol-generating procedures. ${ }^{18}$

Management focuses on symptomatic control of complications arising from COVID-19, as there are no drugs approved for use by the U.S. Food and Drug Administration. However, China has initiated multiple clinical trials for antiviral agents, including interferon-alpha, lopinavir/ritonavir, ribavirin, chloroquine phosphate, and favipiravir, with promising results. ${ }^{19}$

Hospitalization depends on the extent of the disease. Mild and moderate cases are often sent home with instructions to self-quarantine, and depending on oxygen saturations levels, given supplemental oxygen to use with strict return precautions. Upon the need for hospitalization, code status must be discussed, as intubation and cardiopulmonary resuscitation may be required.

\section{GLOBAL IMPACT}

How did we get to this point? The nature of COVID19 , the public health response, and globalization can explain the incredulous and exponential spread of cases. Infectious diseases with global impact have been emerging for the past few decades, including HIV, SARS, avian influenza, and Ebola. Considering the more recent SARS- and MERS-associated coronaviruses, four other human coronaviruses, and the viral structure of the Coronaviridae family, the appearance of a new infectious coronavirus strain causing a global pandemic via human-to-human spread comes as no surprise. ${ }^{20-22}$

The public health response in the U.S. mirrors that seen in Italy which reported its first case of COVID-19 
on February $19^{\text {th }}$, and within a month, the number of positive cases overwhelmed the hospital and health care systems. Some of the issues that led to the massive influx of cases included minimizing the scale of the crisis and its effects and enforcing stay-at-home orders in piece-wise locations after exponential increases in cases had already occurred. ${ }^{23}$ We have seen a similar approach in the U.S., with politicians dismissing public health concerns and continuing to interact with others despite exposure and pending test results. ${ }^{24}$ Initially, the CDC's faulty and delayed test kits prevented quick diagnosis of COVID-19 and effective tracking of potentially infected individuals, increasing the spread. South Korea, alternatively, had an incredibly expansive testing program (conducting the second most tests per capita), which enabled that country to test individuals quickly, isolate the infected, and quarantine their contacts. ${ }^{25}$ In the U.S., local and state governments have become proactive in enacting stay-at-home orders and social distancing after seeing how drastically overwhelmed the hospital systems in New York have become.

With globalization and the ability to easily travel from one country to another, people may become walking fomites or carriers of diseases; respiratory viral pathogens contaminate multiple sites at crowded airports, e.g., the plastic security screening trays, ${ }^{26}$ as well as through flight itself. ${ }^{27}$ Asymptomatic or mildly symptomatic carriers who were traveling globally carried COVID-19 from the localized outbreak in Wuhan, Hubei Province, China, to locations across the globe. The first case was identified in early December 2019, but airlines began to suspend flights to mainland China almost two months later, at the end of January 2020, when over 6,000 people in China had already been identified as infected. ${ }^{28}$ The Cruise Line International Association announced that over 50 cruise lines would temporarily suspend their operations in the U.S. beginning at midnight on March 14, $2020^{29}$; however, this allowed for cruises that began on March 13 to continue, despite the WHO pandemic declaration two days earlier and the infection of over 600 passengers aboard the Diamond Princess cruise ship in February. ${ }^{30}$ Most of these delays can be attributed to concerns over the impact that temporary suspensions would have on corporations, the thousands of individuals they employ, and the overall economy.

\section{FINANCIAL IMPACT}

Financial markets have plummeted and continue to, with concerns that a global recession is looming. With increased stay-at-home directives, businesses have closed, manufacturing has slowed, and thousands of individuals have been laid off or furloughed. ${ }^{31}$ This will most likely continue for months, as controlling and limiting the spread of COVID-19 is essential to not overwhelm the healthcare capacity; since tracing and testing all contacts of infected individuals is no longer feasible, limiting exposure to the virus by mandating stay-at-home orders should reduce human-tohuman transmission. As the current pandemic and exponential growth of cases in the U.S. continues, it seems unlikely that the U.S. will resume business as usual within the next few months, resulting in one of the most devastating impacts of COVID-19-global financial recession. It seems inevitable if keeping the health of the populace is a priority.

\section{HEALTHCARE IMPACT}

As the number of cases continues to grow rapidly, it is imperative that hospitals and public health systems remain vigilant in quick identification, isolation, and reporting of suspected COVID-19 cases. However, there have been many instances of hospitals, from Italy to Brooklyn, becoming overwhelmed and over capacity with the number of patients presenting with COVID-19. ${ }^{32,33}$ Consequently, the U.S. has sent a Navy hospital ship to the New York Harbor to care for patients without COVID-19 to relieve New York hospitals that are currently operating at or over capacity. ${ }^{34}$ There has also been a shortage of ventilators and personal protective equipment (PPE) for healthcare workers in the U.S., partly due to increased demand, a failure to replenish the nation's Strategic National Stockpile, and manufacturing shortages, as half of the world's masks are produced in China where the outbreak first occurred. ${ }^{22}$ With the exponential increase in cases and insufficient or inadequate 
PPE available for healthcare workers, there have been reports of some wearing plastic trash bags when no gowns are available and using the same protective mask for one shift and multiple patient visits. ${ }^{35,36}$ Due to the shortages, the CDC has said that when no masks are available, healthcare workers can use homemade masks, including scarves and bandanas, instead of the originally recommended $\mathrm{N} 95$ respirators that offer much greater protection. ${ }^{5}$ These measures have placed the U.S. healthcare workers at increased risks; for example, the percent of healthcare workers infected with COVID-19 is reported as $18 \%$ in Ohio, and $20 \%$ in both Minnesota and Italy. ${ }^{37,38}$ It is of the utmost importance to protect healthcare workers, as with fewer available frontline workers to care for the population, effective containment of the outbreak may be impossible. Furthermore, they may also become walking fomites themselves and increase the viral load of COVID-19 exposure to patients both with and without the disease.

\section{Conclusion}

A global pandemic secondary to an emerging infectious disease has been expected, if not predicted. It is reasonable that a human coronavirus strain has caused our current situation, as they possess cross-species transmission and environmental resistance. Because of the continuing exponential spread of COVID-19 around the world, it is unlikely that the increase in the number of cases will cease soon, continuing to adversely impact our global economy. Unfortunately, the U.S., among many other countries, has been ill-prepared to handle the outbreak. We can learn from countries that are succeeding in limiting the impact of COVID-19, such as South Korea's quick and efficient testing methods. We must also be sure that our public health systems and hospitals have action plans in place and appropriate levels of personal protective equipment, both now and in the future, as it is of the utmost importance to protect our healthcare workers on the frontline. Most importantly, limiting the transmission of COVID-19 must be our number one priority, both as individuals and as a collective society, because a continued exponential spread will have a devastating impact.
Article citation: Saa L, Iwuji K. Coronavirus Disease 2019: A threat to global health. Southwest Respiratory and Critical Care Chronicles 2020;8(34):4-10

From: Department of Internal Medicine, Texas Tech University Health Sciences Center, Lubbock, Texas

Submitted: $2 / 20 / 2020$

Accepted: 4/5/2020

Reviewer: Kenneth Nugent MD

Conflicts of interest: none

This work is licensed under a Creative Commons Attribution-ShareAlike 4.0 International License.

\section{REFERENCES}

1. Revised U.S. Surveillance Case Definition for Severe Acute Respiratory Syndrome (SARS) and Update on SARS Cases_-United States and Worldwide, December 2003. https:// www.cdc.gov $/ \mathrm{mmwr} /$ preview/mmwrhtml $/ \mathrm{mm} 5249 \mathrm{a} 2$. htm. Accessed March 29, 2020.

2. Lee N, Hui D, Wu A, et al. A major outbreak of Severe Acute Respiratory Syndrome in Hong Kong. $N$ Engl J Med 2003;348(20):1986-1994. doi:10.1056/NEJMoa030685

3. World Health Organization. WHO MERS-CoV Global Summary and risk assessment. https://www.who.int/emergencies/ mers-cov/mers-summary-2016.pdf?ua=1. Published December 2016. Accessed March 29, 2020.

4. He X, Lau EH, Wu P, et al. Temporal dynamics in viral shedding and transmissibility of COVID-19. medRxiv. March 2020: 2020.03.15.20036707. doi:10.1101/2020.03.15.20036707

5. CDC. 2019 Novel Coronavirus (2019-nCoV). Centers for Disease Control and Prevention. https://www.cdc.gov/ coronavirus/2019-ncov/index.html. Published February 11, 2020. Accessed February 20, 2020.

6. World Health Organization. Coronavirus disease 2019 (COVID-19) Situation Report-71. https://www.who.int/docs/ default-source/coronaviruse/situation-reports/20200331sitrep-71-covid-19.pdf?sfvrsn=4360e92b_4. Published March 31, 2020. Accessed March 31, 2020.

7. Onder G, Rezza G, Brusaferro S. Case-fatality rate and characteristics of patients dying in relation to COVID-19 in Italy. JAMA March 2020. doi:10.1001/jama.2020.4683

8. Rajgor DD, Lee MH, Archuleta $\mathrm{S}$, et al. The many estimates of the COVID-19 case fatality rate. Lancet Infect Dis 2020;0(0). doi:10.1016/S1473-3099(20)30244-9

9. Sonnemaker T, Kiersz A. Nearly $30 \%$ of US coronavirus cases have been among people 20-44 years old, the CDC saysshowing that young people are getting sick, too. Business 
Insider. https://www.businessinsider.com/30-percent-us-coronavirus-cases-people-between-ages-20-44-2020-3. Published March 19, 2020. Accessed April 2, 2020.

10. Vardavas CI, Nikitara K. COVID-19 and smoking: A systematic review of the evidence. Tob Induc Dis 2020;18(March). doi:10.18332/tid/119324

11. Hrynowski $Z$. What Percentage of Americans Vape? Gallup.com. https://news.gallup.com/poll/267413/percentageamericans-vape.aspx. Published October 11, 2019. Accessed April 2, 2020.

12. Angeletti S, Benvenuto D, Bianchi M, et al. COVID-2019: The role of the nsp2 and nsp3 in its pathogenesis. $J$ Med Virol doi:10.1002/jmv.25719

13. Geller C, Varbanov M, Duval RE. Human coronaviruses: insights into environmental resistance and its influence on the development of new antiseptic strategies. Viruses 2012;4(11):3044-3068. doi:10.3390/v4113044

14. $\mathrm{Wu} \mathrm{Z,} \mathrm{McGoogan} \mathrm{JM.} \mathrm{Characteristics} \mathrm{of} \mathrm{and} \mathrm{important}$ lessons from the Coronavirus Disease 2019 (COVID19) Outbreak in China: Summary of a Report of 72314 Cases from the Chinese Center for Disease Control and Prevention. JAMA February 2020. doi:10.1001/jama.2020. 2648

15. Fang Y, Zhang H, Xie J, et al. Sensitivity of chest CT for COVID-19: comparison to RT-PCR. Radiology February 2020:200432. doi:10.1148/radiol.2020200432

16. Long $\mathrm{C}, \mathrm{Xu} \mathrm{H}$, Shen $\mathrm{Q}$, et al. Diagnosis of the coronavirus disease (COVID-19): rRT-PCR or CT? Eur J Radiol 2020; 126. doi:10.1016/j.ejrad.2020.108961

17. Why It Takes So Long To Get Most COVID-19 Test Results. NPR.org. https://www.npr.org/sections/health-shots/2020/03/ 28/822869504/why-it-takes-so-long-to-get-most-covid-19test-results. Accessed March 31, 2020.

18. Infection prevention and control during health care when novel coronavirus ( $\mathrm{nCoV}$ ) infection is suspected. https:// www.who.int/publications-detail/infection-prevention-andcontrol-during-health-care-when-novel-coronavirus-(ncov)infection-is-suspected-20200125. Accessed March 29, 2020.

19. Dong L, Hu S, Gao J. Discovering drugs to treat coronavirus disease 2019 (COVID-19). Drug Discov Ther 2020;14(1): 58-60. doi:10.5582/ddt.2020.01012

20. Cockrell AS, Leist SR, Douglas MG, et al. Modeling pathogenesis of emergent and pre-emergent human coronaviruses in mice. Mamm Genome 2018;29(7):367-383. doi:10.1007/ s00335-018-9760-9

21. Reperant LA, Osterhaus ADME. AIDS, Avian flu, SARS, MERS, Ebola, Zika ... what next? Vaccine 2017;35(35, Part A):4470-4474. doi: 10.1016/j.vaccine.2017.04.082

22. Levey N, Christensen K, Phillips A. A disaster foretold: Shortages of ventilators and other medical supplies have long been warned about. Los Angeles Times. https://www. latimes.com/politics/story/2020-03-20/disaster-foretold-shortages-ventilators-medical-supplies-warned-about. Published March 20, 2020. Accessed April 2, 2020.

23. Pisano GP, Sadun R, Zanini M. Lessons from Italy's response to Coronavirus. Harv Bus Rev March 2020. https://hbr. org/2020/03/lessons-from-italys-response-to-coronavirus. Accessed April 2, 2020.

24. Mattingly P, Fox L, Tapper J. Rand Paul is first senator to test positive for coronavirus. CNN. https://www.cnn. com/2020/03/22/politics/rand-paul-coronavirus/index.html. Accessed April 2, 2020.

25. Normile D. Coronavirus cases have dropped sharply in South Korea. What's the secret to its success? Science | AAAS. https://www.sciencemag.org/news/2020/03/coronaviruscases-have-dropped-sharply-south-korea-whats-secretits-success. Published March 17, 2020. Accessed April 2, 2020.

26. Ikonen N, Savolainen-Kopra C, Enstone JE, et al. Deposition of respiratory virus pathogens on frequently touched surfaces at airports. BMC Infect Dis 2018;18(1):437. doi:10.1186/ s12879-018-3150-5

27. Park S, Park JY, Song Y, et al. Emerging respiratory infections threatening public health in the Asia-Pacific region: A position paper of the Asian Pacific Society of Respirology. Respirology 2019;24(6):590-597. doi:10.1111/resp.13558

28. Pham S, Ziady H. Airlines around the world are suspending flights to China as the coronavirus spreads. CNN. https:// www.cnn.com/2020/01/29/business/british-airways-coronavirus/index.html. Published January 29, 2020. Accessed April 2, 2020.

29. Vera A. Major cruise lines suspending operations at US ports for 30 days over coronavirus pandemic. CNN. https://www. cnn.com/travel/article/cruise-line-suspensions-coronavirus/ index.html. Accessed April 2, 2020.

30. Rich M. 'We're in a Petri Dish': How a Coronavirus Ravaged a Cruise Ship. The New York Times. https://www.nytimes. com/2020/02/22/world/asia/coronavirus-japan-cruise-ship. html. Published February 22, 2020. Accessed April 2, 2020.

31. Grim Economic Outlook Grips Markets as Stocks Plummet. The New York Times. https:/www.nytimes.com/2020/03/16/ business/stock-market-drops-recap.html. Published March 16, 2020. Accessed April 2, 2020.

32. Poggioli S. "Every Single Individual Must Stay Home": Italy's Coronavirus Surge Strains Hospitals. NPR.org. https:// www.npr.org/2020/03/19/817974987/every-single-individualmust-stay-home-italy-s-coronavirus-deaths-pass-china-s. Published March 19, 2020. Accessed April 2, 2020.

33. Marquez M, Moghe S. Inside a Brooklyn hospital that is overwhelmed with COVID-19 patients and deaths. CNN. 
https://www.cnn.com/2020/03/30/us/brooklyn-hospitalcoronavirus-patients-deaths/index.html. Published March 31, 2020. Accessed April 2, 2020.

34. Cooper H, Gibbons-Neff T. Navy Hospital Ship Reaches New York. But It's Not Made to Contain Coronavirus. The New York Times. https://www.nytimes.com/2020/03/30/us/ politics/coronavirus-comfort-hospital-ship-new-york.html. Published March 30, 2020. Accessed April 2, 2020.

35. Sanchez T. Coronavirus: Nurses are wearing trash bags at one Bay Area hospital facing a protective equipment shortage. SFChronicle.com.https://www.sfchronicle.com/bayarea/ article/Coronavirus-Nurses-are-wearing-trash-bags-atone-15172777.php. Published April 2, 2020. Accessed April 2, 2020.
36. Associated Press. One mask a day for doctors in virus epicenter of Washington. Modern Healthcare. https://www. modernhealthcare.com/providers/one-mask-day-doctorsvirus-epicenter-washington. Published March 17, 2020. Accessed April 2, 2020.

37. Przybyla H, Fitzpatrick S. Health care workers see coming wave of coronavirus in their ranks. NBC News. https://www. nbcnews.com/news/us-news/health-care-workers-see-wavecoronavirus-coming-their-ranks-n1174271. Accessed April 2, 2020.

38. Remuzzi A, Remuzzi G. COVID-19 and Italy: what next? The Lancet 2020;0(0). doi:10.1016/S0140-6736(20)30627-9 